\title{
IMPORTANCIA DE REGULAR LA MATERNIDAD SUBROGADA EN ECUADOR. CONSIDERACIONES SOBRE NUEVA FORMA DE FILIACIÓN
}

\author{
Ana Fabiola Zamora Vázquez* \\ Martha Paola Loyola Torres**
}

\begin{abstract}
RESUMEN. La maternidad subrogada es un problema latente en la realidad actual que no tiene regulación normativa en Ecuador, este trabajo de investigación pretende demostrar la necesidad de contar con una ley que garantice seguridad jurídica a las personas, sobre todo a las familias que han optado por esta forma de gestación derivada de las Técnicas de Reproducción Asistida para tener hijos, pues el aspecto filiatorio juega un papel preponderante en este ámbito y al existir vacio legal demuestra que el derecho sufre retraso en relación a la ciencia y tecnología que avanza a pasos agigantados. También se hace referencia a Derecho Comparado identificando paises que prohíben la maternidad subrogada, por los cuestionamientos sobre la falta de confianza, es por esta razón que diversas legislaciones se encuentran preocupadas por reglamentarla y solucionar el problema de filiación.
\end{abstract}

PALABRAS CLAVE. Maternidad subrogada Filiación. Familia. Reproducción asistida.

ABSTRACT. Surrogacy is a latent problem in the current reality that does not have normative regulation in Ecuador. This research paper aims to demonstrate the need to have a law that guarantees legal certainty to people, especially to families who have opted for this form of gestation derived from techniques of assisted reproduction to have

\footnotetext{
* Abogada. Docente de la Universidad Católica de Cuenca - Ecuador. Especialista en Docencia Universitaria. Magister en Derecho Civil y Procesal Civil. Doctoranda en la Universidad de Castilla la Mancha. Correo electrónico: afzamorav@ucacue.edu.ec

** Abogada. Docente de la Universidad Católica de Cuenca - Ecuador. Especialista en Docencia Universitaria. Magister en Derecho Civil y Procesal Civil. Correo electrónico: mployolat@ucacue.edu.ec
} 
children. The filial aspect plays a preponderant role in this area and the existence of legal void proves that the law is lagging behind in relation to science and technology that are advancing by leaps and bounds. Reference is also made to comparative law by identifying countries that prohibit surrogacy, due to the questions about lack of confidence, which is why various legislations are concerned with regulating and solving the Filiation problem.

KEYWORDS. Motherhood surrogate. Filiation. Family. Assisted reproduction.

\section{NOCIONES GENERALES DE LA MATERNIDAD SUBROGADA}

Las técnicas que han avanzado en la parte genética permiten hoy en día tener hijos mediante la fecundación artificial, es decir, una mujer puede ser madre sin relación sexual, pues estas técnicas no constituyen solamente tratamiento de esterilidad, sino un aporte del derecho a la fertilidad, que permite reivindicar un derecho a la misma. Además, este acelerado proceso ha desatado contradicciones sobre todo desde el punto de vista cultural, desde la perspectiva de la separación entre sexualidad y procreación, o por el contrario la procreación sin sexualidad, tornándose en una nueva situación de análisis; de esta forma se realiza la primera técnica de fecundación en la que nace Louise Brown, en 1978 ${ }^{1}$, quedando de esta forma señalado que el embarazo y la sexualidad se pueden separar.

Al existir estos procedimientos que cada día son más avanzados entendemos que están vinculados de manera profunda con la dignidad del ser humano, el derecho de nacer, de identidad y el más importante y fundamental el derecho a la vida. Los temas vinculados a la procreación han ido tomando protagonismo social y jurídico, sobre todo por los hoy conocidos "Derechos Reproductivos".

Es por ello la importancia de definir el significado de los verbos "subrogar" y "gestar", así como de la expresión "maternidad”, que manifiestan los siguiente:

Subrogación. Sustitución, realizada por voluntad de las partes o por imperativo legal, de una persona (subrogación personal) o de una cosa (subrogación real) en el lugar que antes ocupaba otra, de forma que adquiere tanto los derechos como las obligaciones de ésta. ${ }^{2}$

Gestación. - Las fases finales del desarrollo del animal en el óvulo fertilizado tienen lugar en la matriz o útero situado dentro del abdomen de la madre. Este estado de expansión del útero y su contenido, que termina con el alumbramiento y dura unos 280 días en los seres humanos, se llama gestación o preñez. ${ }^{3} \mathrm{Y}$, por último en cuanto a la definición de "maternidad" el Diccionario de la Real Academia de la Lengua expresa: es el estado o cualidad de madre. ${ }^{4}$

${ }^{1}$ Es la primera persona que nace a través de las Técnicas de Reproducción Humana Asistida en el año de 1978.

${ }^{2}$ Fuente: "Diccionario Fiel web" https://www.fielweb.com/Index.aspx?145abf6ik651\#app/herramientas. Fecha de consulta: 16/05/2019

${ }^{3}$ Fuente: "Diccionario Fiel web" https://www.fielweb.com/Index.aspx?145abf6ik651\#app/herramientas. Fecha de consulta: 16/05/2019

${ }^{4}$ Fuente: "Real Academia de la Lengua Española". Disponible en: https://dle.rae.es/?id=YZ2is6w. Fecha de consulta: 06/05/2019. 
La maternidad subrogada tiene otras acepciones como maternidad de alquiler, gestación por sustitución, vientre de alquiler, maternidad portadora o maternidad sustitutiva, etc., el problema implica las consecuencias sobre los cambios que se deben dar en diferentes materias, pues la maternidad subrogada se realiza por medio de las técnicas de reproducción asistida.

Por lo tanto, la maternidad subrogada se puede definir como:

...( ) un compromiso entre una mujer llamada "mujer gestante", a través del cual esta acepta someterse a Técnicas de Reproducción Humana Asistida, para llevar la gestación a favor de una persona o pareja, llamados "subrogantes" a quienes deben entregar el niño el momento del nacimiento, sin que exista vinculo de filiación con la gestante, sino con las personas que tienen calidad de subrogantes. ${ }^{5}$ El conocido Informe Palacios, nos aporta una definición de la gestación por sustitución señalando: "Es una forma de maternidad biológica por la cual una mujer acepta llevar a cabo una gestación por acuerdo con una pareja heterosexual (matrimonio o pareja estable) irreversiblemente estéril, que responsabilizará la maternidad y paternidad de la descendencia a todos los efectos" ${ }^{\text {. }}$

Dentro de la maternidad subrogada existen aspectos que deben ser analizados como el caso de existir una mujer que da su consentimiento para prestar su cuerpo con la finalidad de que se implante un embrión que no le pertenece biológicamente, debiendo realizar la entrega una vez terminada la etapa de gestación; desde otra perspectiva también es preciso la existencia de un contrato que dentro de su clasificación puede ser oneroso o gratuito, en el que entre sus cláusulas constará renunciar a sus derechos como madre, aclarando la situación de que realizó la gestación pero que el material genético no le corresponde; salvo el caso que además de gestar también sea donadora de óvulos.

En el caso de encontrarnos ante una pareja homosexual, uno de los miembros de la pareja será el que aporte su gameto, pero necesariamente debe contar con la existencia de una madre sustituta para llevar a cabo la gestación a través de la ovodonación bien por parte de la propia mujer que va a gestar o bien por otra diferente.

De todo lo mencionado con anterioridad podemos deducir "La gestación por sustitución (o maternidad subrogada) es un supuesto de reproducción humana asistida mediante el cual una mujer se compromete a gestar un bebé concebido a través de técnicas de reproducción asistida para que otra u otras personas puedan ser padres". ${ }^{7}$

\section{ASPECTOS DE MATERNIDAD SUBROGADA EN ECUADOR.}

La maternidad subrogada en el Ecuador debe ser regulada, por cuanto es un tema de mucho debate en la actualidad y no puede seguir aislado de la realidad, se necesita que el Estado intervenga con la finalidad de legislar varios puntos de vista como el social, jurídico,

${ }^{5}$ SCOTTI, L. "El reconocimiento de la "maternidad subrogada": una realidad colmada de interrogantes sin respuestas jurídicas". En Pensar en Derecho, 2013, Nº1, Pág. 274.

${ }^{6}$ Informe de la Comisión Especial de Estudio de la Fecundación 'In Vitro' y la Inseminación Artificial Humanas. Congreso de Diputados. España. Cortes Generales.

7 Álvarez Rodríguez, Aurelia \& Carrizo Aguado, David. "Tratamiento legal del contrato de gestación por sustitución en el Derecho Internacional Privado español a la luz de la STS de 6 de febrero de 2014. Dime niño, ¿de quién eres...?.2014 
ético, etc. Todos estos aspectos dan lugar a la trascendencia de establecer una ley especifica que contemple las Técnicas de Reproducción Humana Asistida de forma general, y uno de sus aspectos particulares hagan referencia a la Maternidad Subrogada.

El artículo 66 de la Constitución de la República establece en el numeral 3 literal d: "La prohibición del uso de material genético y la experimentación científica que atenten contra los derechos humanos". El Ministerio de Salud Pública y la Comisión Nacional de Bioética en Salud emiten el Criterio y Recomendaciones Bioéticas sobre la Maternidad Subrogada en Ecuador estableciendo: "en el Ecuador se efectúan procesos de maternidad subrogada desde el año 1993, sin que este lapso se haya establecido regulaciones legales que la normen".

De lo referido en el párrafo anterior, la situación mencionada es preocupante por cuanto la falta de regulación de este avance de la ciencia conlleva un problema desde diversos ámbitos sobre todo familiar, en el que se debe realizar un debate que intervengan personas con conocimiento tanto de la parte médica como legal para alcanzar la solución de este problema. Esta situación debe ser codificada de manera urgente por la frecuencia con la que se presentan estos casos, que tienen como resultado el nacimiento de un ser humano que debe tener garantías y respuesta de la justicia ecuatoriana, más aún con las reformas el Libro I del Código Civil respecto al matrimonio que a través de Sentencia No. 11-18-CN/19 de la Corte Constitucional, publicada en Registro Oficial Suplemento 96 de 8 de Julio del 2019, cambia la perspectiva de manera significativa, eliminando la procreación dentro de este artículo, estableciendo: "Matrimonio es un contrato solemne por el cual dos personas se unen con el fin de vivir juntos y auxiliarse mutuamente". Esta circunstancia deja abiertas interrogantes como: ¿Por qué es importante la maternidad subrogada? ¿Por qué debe ser regulada en Ecuador?; cobrando importancia en distintas situaciones como cuando existen casos de infertilidad dentro de las parejas o el caso de matrimonio en parejas del mismo sexo que desean tener hijos con material genético propio a través de la maternidad subrogada, etc.

Existen varios aspectos que se pueden estudiar desde el punto de vista civil como el contrato de los dueños del material genético y la mujer que alquila su vientre, la cuestión de diversidad de tipos de familia, siendo el tema que nos interesa considerar a la filiación como argumento principal por el vínculo jurídico social que genera por la diversidad de concepciones tanto para la madre genética como gestante. La diferencia entre madre genética y gestante radica en que la primera colabora con el material genético y la segunda hace referencia a la mujer que presta su útero para promover la gestación.

La falta de norma jurídica sobre el tema induce a la ilegalidad, es necesario regular sobre todo para la determinación de la filiación en el caso de maternidad subrogada los acuerdos de gestación por sustitución, ya que el Ecuador se encuentra en un letargo legal en el tema al no tratar cuestiones como reproducción asistida, que de cierta forma dan paso a la solución de ciertos problemas en las uniones de hecho o matrimonio de personas del mismo sexo permitidas en nuestro Estado; los numerosos conflictos legales que presentan las técnicas de reproducción humana asistida se abordan por el interés de saber el establecimiento sobre las relaciones de filiación, pues para el derecho habitual la filiación se establece a través de la genética; considerando que en la maternidad subrogada se pueden presentar dos situaciones, que la mujer aporte su material (óvulos) y por razones ajenas a su voluntad tenga que contratar un vientre; o, el caso que la mujer gestante aporte también 
el material genético, en este tipo de situaciones en algunos países el primer caso es legal y el segundo caso con cualesquiera otros se presenten son calificados como ilícitos.

Es significativo realizar un avance legislativo para reforzar este vacío legal, pues al ser un Estado Constitucional de derechos y justicia social en el que reconoce la familia en sus diversos tipos, ${ }^{8}$ debe garantizar la filiación, esto permitiría hacer efectivos los derechos, sobre todo que se respete y promueva el ejercicio de las nuevas formas de paternidad y maternidad que se han implementado con el avance de la ciencia; nuestro país debe involucrarse para cumplir con temas tan trascendentes como acceder a una verdadera diversidad familiar, aclarando siempre que quienes se someten a estos procedimientos deben actuar de manera responsable. La Constitución de 1998 no acoge diversidad de tipos de familia por cuanto se puede considerar una evolución de la parte legislativa para el año 2008.

En el Ecuador se ha tratado en el tema de salud de legalizar las Técnicas de Reproducción Humana Asistida, asílo ha informado William Garzón Ricaurte, quien fuere Asambleísta y Presidente de la Comisión de Derecho a la Salud, en este contexto el 28 de marzo de 2016 se presentó la iniciativa de proyecto de ley siendo calificado el 12 de mayo del mismo año por el Consejo de Administración Legislativa (CAL), presentándose el informe del primer debate el 15 de marzo de 2017. Con fecha 11 de abril de 2018, la Comisión del Derecho a la Salud, aprobó con el voto afirmativo de diez Asambleístas presentes la moción referente a la metodología para aprobación del Informe de Segundo Debate. Lo relevante de este borrador que constituiría el Código Orgánico de la Salud es la regulación de las técnicas de reproducción humana asistida que constaría en el artículo $189^{9}$, a pesar de existir el proyecto no se termina por debatir el tema y sigue quedando en el abandono, además que la ley civil no establece nada relacionado a esta cuestión y por ende tampoco a la filiación en estos casos.

En nuestro país existen seis centros certificados por la Red Latinoamericana de Reproducción Humana Asistida: 1) Biogepa, Centro de Reproducción Humana, 2) CERHVALENCIA CIA, LTDA, 3) Clínica INFES, 4) CONCEBIR, Unidad de Fertilidad y Esterilidad, 5) INNAIFEST, 6) Centro Nacional de Reproducción Asistida, Unidad de Fertilidad del Hospital Alcívar. En nuestro país los Procedimientos Técnicos de Reproducción Asistidos reportados a la Red Latinoamericana hasta el año 2015, son los siguientes ${ }^{10}$ : FETO = embrión autólogo congelado iniciado 106; FP = preservación de la fertilidad 4; FRESCO = iniciado FIV 328 / ICSI ciclos; OD = ciclos iniciados para la transferencia de

\footnotetext{
${ }^{8}$ Constitución del Ecuador. Art. 67. Se reconoce la familia en sus diversos tipos. El Estado la protegerá como núcleo fundamental de la sociedad y garantizará condiciones que favorezcan integralmente la consecución de sus fines. Estas se constituirán por vínculos jurídicos o de hecho y se basarán en la igualdad de derechos y oportunidades de sus integrantes.

${ }^{9}$ Proyecto de Ley - Código Orgánico de la Salud. Artículo 189. Reproducción humana asistida. - Las técnicas de reproducción humana asistida, podrán realizarse en el país cumpliendo con principios bioéticos universales y con las normas, requisitos y regulaciones determinados por la Autoridad Sanitaria Nacional, incluyendo los que atañen al acceso a estos métodos. Se prohíben las contraprestaciones económicas o compensaciones de cualquier tipo a cambio de la donación de gametos o embriones o de la subrogación del vientre, con la excepción del pago de los costos de la atención durante la gestación y el parto. Los establecimientos prestadores de servicios de salud que brinden este tipo de servicios deberán contar con protocolos explícitos de consentimiento informado.

${ }^{10}$ Fuente: Red Latinoamericana de Reproducción Asistida (REDLARA). Disponible en: http:// www.redlara.com/aa_espanhol/quem_centros.asp.
} 
embriones frescos o congelados utilizando ovocitos donados 149; Otro= la transferencia de embriones derivados de ovocitos autólogos y donados congelados $/$ descongelados $=3$.

Estos procedimientos deben ser regulados para garantizar la concepción, los derechos de los padres, del nasciturus, de los médicos intervinientes en el proceso, pero sobre todo de la situación de filiación que se desprende de estos métodos que de cierta forma han ayudado a personas a cumplir sus expectativas de ser padres.

De acuerdo a la información de la Red Latinoamericana de Reproducción Asistida en el Registro Latinoamericano de bebés nacidos por estas técnicas desde 1990 hasta 2012 en el Ecuador existen 1514 casos representando el 1.2\% con relación a Brasil con 56674 que constituye el 44,2\% en América Latina; en el mismo informe entre la media de embriones transferidos y parto por tasa de embarazos por cada 2,2 embriones transferidos existe un $30 \%$ de tasas de parto, ante esta realidad se puede determinar que la falta de regulación de la gestación por sustitución no evita que esta se lleve a cabo, es por ello obligatorio proporcionar una respuesta legal sobre todo al ámbito de Derecho de Familia, pues de no ser regularizada puede desembocar conflictos sociales, de discriminación y perjuicios para los padres que han optado por esta forma de procreación, así como para los niños, por no tener contexto jurídico que ampare estas prácticas. Es trascendental una normativa que contemple la maternidad subrogada y permita su acceso en condiciones de igualdad.

La necesidad de legislar este vacío legal surge por la cantidad de conductas que se han ido consumando, que pueden rebasar el límite de la legalidad por no existir la norma.

Dentro de página web de los centros mencionados con anterioridad solamente la Clínica INNAIFEST presenta soporte legal y hace referencia a que todos los procedimientos que realizan son mediante consentimiento informado, y además manifiesta: "en los procedimientos que intervienen terceras personas, como es el caso del Útero Subrogante, donante de óvulos y/o embriones, nuestro Centro cuenta con un profesional de experiencia en los aspectos legales que estos procedimientos implican". ${ }^{11}$

\section{IMPORTANCIA DE LA FILIACIÓN DENTRO DE LA MATERNIDAD SUBROGADA.}

Para tratar este punto en primera instancia se define el termino filiación como: "el vínculo legal que se entabla entre dos personas, calificadas por la ley como "padre" o "madre", en un extremo, e "hijo" e "hija", en el otro. Tiene así lugar, en consecuencia, las llamadas filiación paterna o materna". (Cornú, 1998). La Constitución de la República en el artículo 69 numerales 5, 6 y 7 expresan la protección de los derechos de las personas que integran la familia: el Estado promoverá la corresponsabilidad materna y paterna y vigilará el cumplimiento de los deberes y derechos recíprocos entre madres, padres, hijas e hijos. Estos últimos tendrán los mismos derechos sin considerar antecedentes de filiación o adopción y no se exigirá declaración sobre la calidad de la filiación en el momento de la inscripción del nacimiento y ningún documento de identidad hará referencia a ella. Resulta indudable que el Derecho de Familia sobre todo cuestiones de filiación, debe progresar de forma conjunta con los avances científicos y tecnológicos de la medicina, que

\footnotetext{
11 https://www.innaifest.com.ec/servicios/soporte-legal: Consulta 06/05/2019
} 
en la actualidad confieren varias formas de procreación, que vienen acompañadas de problemas que vinculan de manera fundamental a la ética, por lo tanto, nuestro país necesita normas jurídicas que garanticen los intereses de quienes han optado por estos medios.

El artículo 24 del Código Civil en su Título Preliminar expresa: Se establece la filiación, y las correspondientes paternidad y maternidad:

a) Por el hecho de haber sido concebida una persona dentro del matrimonio verdadero o putativo de sus padres, o dentro de una unión de hecho, estable y monogámica reconocida legalmente;

b) Por haber sido reconocida voluntariamente por el padre o la madre, o por ambos, en el caso de no existir matrimonio entre ellos; $y$,

c) Por haber sido declarada judicialmente hijo de determinados padre o madre.

El parto determina la filiación materna, este es el problema principal en el Ecuador, puesto que, al utilizar técnicas de reproducción humana asistida, al no existir norma jurídica que haga referencia, no se puede establecer medios como convenios, renuncia de la filiación por parte de la mujer que estuvo a cargo de la gestación a favor de la contratante, etc., por lo tanto, la regulación sobre aspectos de genética debe considerar en primera instancia los principios constitucionales y tratados internacionales relacionados con la mujer, familia y menores, dentro de los cuales esté involucrado el estado Ecuatoriano, ya que entran en discusión derechos como a la vida, libertad, intimidad personal y familiar, asegurándose que la ley este en completa concordancia con los Derechos Humanos relacionados con los menores y la familia.

En este punto los legisladores deberán manifestarse sobre un tema relevante como controvertido, sobre la importancia de la regulación que permita distinguir el origen biológico y el entorno tanto de cuestiones afectivas y sociales por filiación, o si deben establecer una serie de normas que relacionen la filiación legal con la filiación de ipso. ${ }^{12}$

Se debe recalcar que este tema proyecta varias perspectivas tanto en el ámbito legal como ético, al tratarse de argumento que involucran de manera directa al derecho civil y de familia, pues la filiación se puede determinar desde tres puntos de vista: legal, voluntaria y judicial. La filiación legal depende de la ley; la voluntaria depende del reconocimiento que puede ser expreso o tácito; y, judicial resulta de la sentencia que declara la paternidad o maternidad. El reconocimiento es un actojurídico familiar, destinado a establecer el vínculo jurídico de la filiación. ${ }^{13}$

De acuerdo a lo mencionado en párrafos anteriores la filiación es la relación jurídica existente entre padres e hijos, de ella provienen derechos y obligaciones; es decir, es la forma de determinar quiénes son padres de un niño o niña. El objetivo legal dentro del proceso de maternidad subrogada es que los progenitores del bebé sean reconocidos legalmente como padres, esto es, que ambos miembros de la pareja obtengan la filiación, por ser considerados los verdaderos padres del niño.

\footnotetext{
${ }^{12}$ MORALES LIMONES, PILAR BLANCO ¿̇Y tú de quién eres?, Lección inaugural de la Universidad de Extremadura, curso académico 2010/2011.

${ }^{13}$ BOSSERT, GUSTAVO \& ZANNONI, EDUARDO. Manual de Derecho de Familia. Sexta Edición. Editorial Astrea. Buenos Aires, 2004, pág. 450.
} 
Por lo tanto, el Derecho de Filiación hace referencia, a su vez, al conjunto de normas jurídicas relativas al emplazamiento llamado también "determinación" o "establecimiento" - de las relaciones paterno materno filiales en los tres ámbitos posibles actualmente conocidos: a) la procreación por naturaleza; b) la generación por los más diversos métodos de fecundación artificial, y c) la filiación adoptiva. (Mendez Costa, 1986).

En el concepto filiación, la doctrina contemporánea ha puesto énfasis en los nuevos métodos de procreación desarrollados por la ciencia la fecundación artificial homologa (esta se realiza entre cónyuges), y heteróloga (se realiza con material genético de donantes), ya que "representan un fenómeno que implicó apartar más la noción de filiación de su apoyatura biológica". (La Cruz Berdejo, Sancho Rebullida, \& Luna Serrano, 1997)

En los distintos países donde se realiza el proceso de maternidad subrogada, pueden existir distintos fundamentos legales para determinar la filiación del menor a favor de los comitentes, podrá fundarse en el vínculo biológico y aporte de ADN, en la voluntad pro creacional, en un vínculo contractual, etc.

De manera general la filiación de los nacidos con las técnicas de reproducción asistida se debe regular a través de la ley civil, la inscripción en el Registro Civil manifestará los datos con la finalidad garantizar la identificación, el Código Orgánico de la Niñez y Adolescencia del Ecuador en su artículo 36 establece las normas para la identificación, ${ }^{14}$ así como también hace referencia a la filiación en su artículo 99 que establece: Unidad de filiación. - Todos los hijos son iguales ante la ley, la familia y la sociedad. Se prohíbe cualquier indicación que establezca diferencias de filiación y exigir declaraciones que indiquen su modalidad.

Es en la filiación donde derivan problemas de maternidad subrogada, por cuanto se debe determinar el contexto jurídico respecto de los menores que han sido concebidos a través de estas técnicas, pues en nuestro país al nacer un niño bajo estas circunstancias, de manera automática se lo vincula con la mujer que lo dio a luz, no se reconoce a la madre que aportó el material genético como tal, además de que aspectos relacionados con filiación son de carácter público y no pueden cambiar por un acuerdo de partes.

\subsection{Casos de maternidad Subrogada}

Con la implementación de las Técnicas de Reproducción Asistida y derivada de estas la maternidad subrogada ha presentado casos de problemas jurídicos entre los padres

${ }^{14}$ En la certificación de nacido vivo, que deberá ser emitida bajo la responsabilidad del centro o institución de salud pública o privada que atendió el nacimiento, constará la identificación dactilar de la madre y la identificación plantar del niño o niña recién nacido o nacida. En casos de inscripción tardía se deberá registrar en la ficha respectiva la identificación dactilar del niño, niña o adolescente. Cuando se desconozca la identidad de uno de los progenitores, el niño, niña o adolescente llevará los apellidos del progenitor que lo inscribe, sin perjuicio del derecho a obtener el reconocimiento legal del otro progenitor. Si se desconoce la identidad o domicilio de ambos progenitores, el niño, niña o adolescente se inscribirá por orden judicial o administrativa, con dos nombres y dos apellidos de uso común en el país. Se respetará el nombre con el cual ha sido conocido y se tomará en cuenta su opinión cuando sea posible. La inscripción podrá ser solicitada por la persona encargada del programa de protección a cargo del niño o niña o por la Junta de Protección de Derechos. Practicada la inscripción, el Jefe Cantonal del Registro Civil pondrá el caso en conocimiento de la Defensoría del Pueblo de la jurisdicción correspondiente, para que inicie las gestiones extrajudiciales tendientes al esclarecimiento de la filiación del niño o niña y posterior reconocimiento voluntario o entable la acción para que sea declarada judicialmente. 
biológicos y la madre gestante o portadora, uno de ellos es el caso "Baby M", siendo uno de los más controvertidos y uno de los primeros en lo que ha gestación por sustitución se refiere. En New Jersey, perteneciente a los Estados Unidos de América, la señora Whitehead suscribió un contrato en el 1985 renunciando a sus derechos como madre y comprometiéndose a conceder la custodia a la familia Stern; el problema se presenta el momento del nacimiento de la niña, por cuanto la madre portadora, no quiere cumplir con el contrato; para el año 1987, el juez falló a favor de los padres legales, los Stern argumentando la existencia del contrato completamente legal y que los diez mil dólares recibidos son por los servicios de la gestante más no eran el precio del bebé.

En el año 2014, la familia Farnell de australianos viajan a Tailandia y realizan un contrato con Pattaramon Chanbua sobre servicio de alquiler de vientre, quien da a luz una niña y un niño y deciden regresar a casa con Pipah, la gemela que no tiene síndrome de Down. A partir de ese momento Gammy vive con la madre de alquiler.

En Israel existe uno de los casos de maternidad subrogada que más ha llamado la atención, una bebé nace después de dos años de haber fallecido su madre, el viudo quiso cumplir los deseos de su esposa quien no pudo terminar su tratamiento de fertilidad por su enfermedad, antes de su fallecimiento le solicito a su marido que intentará tener un hijo con los embriones que tenían congelados. El proceso fue complejo por el hecho de realizar una gestación con material genético de una mujer fallecida, era el primer caso que se presentaba en este país, incluso se vio obligado a asistir a una organización llamada "New Family" que lo ayudo para que el fiscal autorice la utilización de los embriones. Una vez que contó con la autorización el hombre pudo cumplir la voluntad de su esposa llevando a cabo la gestación en una mujer de los Estados Unidos.

\subsection{Derecho Comparado sobre maternidad subrogada}

El derecho a procrear ha evolucionado de manera significativa, los derechos reproductivos se consolidaron en el ámbito universal de las Conferencias mundiales sobre Población y Desarrollo celebrada en EL Cairo en 1994, y posteriormente la celebrada en Beijing en 1995 sobre la Mujer, donde el contenido de estos derechos se concreta en el reconocimiento del derecho básico de todas las parejas e individuos a decidir libre y responsablemente el número de hijos, el espaciamiento de los nacimientos y el intervalo entre estos, y a disponer de la información y de los medios para ello y el derecho a alcanzar el nivel más elevado de salud sexual y reproductiva. ${ }^{15}$

\subsubsection{España}

La ley española 35, del 22 de noviembre de 1988, al igual que la actual ley 14, del 22 de mayo de 2006 que la deroga, mantienen la prohibición de la maternidad subrogada, su artículo uno literal b manifiesta: "Regular la aplicación de las técnicas de reproducción humana asistida en la prevención y tratamiento de enfermedades de origen genético, siempre que existan las garantías diagnósticas y terapéuticas suficientes y sean debidamente autorizadas en los términos previstos en esta Ley". Es decir estas técnicas son legales

15 FERNANDEZ RUIZ-GALVEZ, E. "Mujeres y Técnicas de Reproducción Artificial. ¿Autonomía o Sujeción? Editorial Comares. Granada, 2002, pág. 161. 
en este país bajo los parámetros de la norma jurídica, mientras que lo relativo a la gestación por sustitución no está permitida de acuerdo a lo manifestado en su artículo $10^{16}$.

\subsubsection{Georgia}

En este país la maternidad subrogada está permitida desde hace aproximadamente veinte años, existen requisitos que deben cumplirse para la aplicación de las técnicas de reproducción humana asistida como por ejemplo el hecho de permitirse solo en parejas heterosexuales que sean casadas, no requiere de sentencia judicial sino se lleva a cabo través de la adopción con la finalidad de garantizar la filiación.

\subsubsection{Chile}

En Chile no se encuentra regulada la maternidad subrogada, pero existen leyes que hacen referencia a Derechos de Reproducción como de filiación, la Constitución Política de Chile manifiesta en su artículo 1 la libertad de las personas y la familia como núcleo de la sociedad. También cuenta con la Ley $19.585^{17}$ en la que se encuentran aspectos relativos a la filiación respecto de la Reproducción Asistida.

\subsubsection{Colombia}

En Colombia no existe ley que trate sobre maternidad subrogada, pero existe jurisprudencia emitida por la Corte Constitucional a través de la sentencia T-968-0918, hace

${ }^{16}$ Artículo 10. Gestación por sustitución.

1. Será nulo de pleno derecho el contrato por el que se convenga la gestación, con o sin precio, a cargo de una mujer que renuncia a la filiación materna a favor del contratante o de un tercero.

2. La filiación de los hijos nacidos por gestación de sustitución será determinada por el parto.

3. Queda a salvo la posible acción de reclamación de la paternidad respecto del padre biológico, conforme a las reglas generales.

${ }^{17}$ Artículo 182 establece: "el padre y la madre del hijo concebido mediante la aplicación de técnicas de reproducción humana asistida son el hombre y la mujer que se sometieron a ellas. no podrá impugnarse la filiación determinada de acuerdo a la regla precedente, ni reclamarse una distinta".

${ }^{18}$ Resolución: Primero. - LEVANTAR la suspensión del término decretada para decidir el presente asunto.

Segundo. - CONFIRMAR la providencia proferida por la Sala de Casación Civil de la Corte Suprema de Justicia del 24 de febrero de 2009, que a su vez confirmó el fallo de primera instancia del 10 de diciembre de 2008 de la Sala de Familia del Tribunal Superior de Distrito Judicial de Cali, por medio del cual se dejó sin efectos la sentencia 395h del 29 de agosto de 2008, proferida por el Juzgado Décimo de Familia de Cali.

Tercero. ORDENAR al Juzgado Décimo de Familia de Cali el cumplimiento, sin dilación alguna, de las medidas de protección ordenadas en el punto 8.4 de la presente sentencia, encaminadas a lograr el restablecimiento de los derechos de los menores y de la madre, hasta tanto se decidan definitivamente los procesos de pérdida de la custodia y cuidado personal que adelanta el Juzgado Promiscuo Municipal de Vijes y el de pérdida de la patria potestad adelantado por el Juzgado Décimo de Familia de Cali, juzgados que serán notificados de la presente providencia.

Cuarto. ORDENAR al Instituto Colombiano de Bienestar Familiar el acompañamiento del proceso de reencuentro de los menores con su madre, y adelantar todas las gestiones dentro del ámbito de su competencia para garantizar, a la mayor brevedad posible, el cumplimiento de las medidas de protección ordenadas en el punto 8.4 de la presente sentencia, sin perjuicio de las funciones de vigilancia superior, de prevención, control de gestión y de intervención ante las autoridades judiciales asignadas por la ley a la Procuraduría General de la Nación a través de la Procuraduría Delegada para la Defensa de los Derechos de la Infancia, la Adolescencia y la Familia.

Quinto. - LÍBRENSE las comunicaciones de que trata el artículo 36 del Decreto 2591 de 1991, para los efectos allí contemplados.

Cópiese, notifíquese, insértese en la gaceta de la Corte Constitucional y Cúmplase. 
referencia al caso de Saraí, esta mujer establece acción de tutela contra el Juzgado Décimo de Familia de Cali por haberla separado de sus hijos, los mismos que fueron concebidos por medio de maternidad subrogada, intentó ayudar a una pareja con su propio material genético, pero no tuvo resultado, después de un tiempo con sus óvulos y los espermatozoides de Salomón se consiguió un embarazo gemelar. El momento del parto Saraí decide no entregar a los niños incumpliendo un contrato verbal, luego de un tiempo el Instituto Colombiano de Bienestar Familiar le retiró la custodia alegando peligro la salud de los menores por el lugar donde vivía. El padre Salomón inició un proceso de privación de la patria potestad contra Saraí e interpuso demanda para solicitar permiso de salida de país de los menores obteniendo el consentimiento por el Juez Décimo de Familia de Cali el mismo que alega que los niños fueron fruto de un contrato de maternidad subrogada y que a partir del nacimiento la madre biológica tenía que haber cumplido el contrato renunciando a los menores. Posteriormente, con varios litigios por la custodia de los menores, el caso llegó a la Corte Constitucional la misma que consideró que los derechos de los niños están amparados por lo que la separación de los menores de su madre biológica puede proceder si la madre no puede cumplir con los aspectos relacionados a la protección de los menores, esto no se pudo demostrar por parte del padre, y así tenga mejores condiciones económicas no es razón suficiente para que los niños vivan con él. También la Corte Constitucional se refirió a que la maternidad subrogada no se encuentra en la legislación colombiana y que los discernimientos emitidos por la parte doctrinal no son suficientes para el establecimiento del contrato de maternidad. En virtud de todo lo mencionado en líneas anteriores la Corte Constitucional resuelve conceder la protección de los niños a la madre biológica (Saraí) permitiendo al padre (Salomón) visitarlos.

\section{CONCLUSIONES.}

Tomando en consideración que los temas de Técnicas de Reproducción Asistida y dentro de estos la maternidad subrogada se ha convertido en una realidad palpable en la mayor parte de países, se necesita en nuestro país implementar la normativa sobre la materia con la finalidad de garantizar los derechos y las obligaciones de los intervinientes, motivando una regulación que permita a los jueces una interpretación y aplicación clara, para resolver los incidentes que se puedan presentar en el tema, pues el avance de la ciencia y la tecnología ha generado controversias en el ámbito derecho de familia que se encuentra en constante evolución como resultado de las nuevas tecnologías reproductivas, las relaciones de familia han sufrido cambios profundos, y se han convertido en problemas que deben ser resueltos, es aquí donde el legislador debe cumplir su rol ofreciendo respuestas a través de una normativa que atienda los principales aspectos como la determinación de la filiación, ya que no existen previsiones legales para el tema.

En este sentido el régimen de filiación que se encuentra en el Código Civil en el artículo 24 y el Código de la Niñez y Adolescencia en el artículo 99, respecto de la filiación debe hacer un cambio con la finalidad de concordar el vínculo biológico con el jurídico, respetando la identidad del niño, las técnicas de reproducción humana y dentro de esta la maternidad subrogada, obliga a reformular criterios, el hecho de no existir conexión biológica entre los padres y el niño, no puede ser obstáculo para que desde el punto de vista legal se los considere como tal, pues han tenido la voluntad y el consentimiento de traer un hijo al mundo con todas las obligaciones que se generan. Por lo tanto, la filiación se debe establecer siempre 
en beneficio del "interés superior del niño", por ello la ley debe garantizar la maternidad legal a quien realmente ha deseado serlo.

Se emplean muchos argumentos para que se regule este tema, sobre todo para garantizar la seguridad jurídica de las partes, es por ello trascendental se legisle este tema que se encuentra latente en el contexto social, médico, jurídico, etc., existiendo la necesidad de establecer normas para evitar que conductas ilegitimas rebasen estas prácticas.

Por todo lo expuesto en líneas anteriores, se debe legislar y controlar la maternidad subrogada con la finalidad de evitar problemas en su proceso y garantizar de manera efectiva los derechos de las partes.

\section{BIBLIOGRAFÍA CONSULTADA}

BOSSERT, GUSTAVO \& ZANNONI, EDUARDO. Manual de Derecho de Familia. Sexta Edición. Editorial Astrea. Buenos Aires, 2004, pág. 450.

Constitución de la República del Ecuador 2008. Asamblea Constitucional- Editorial: Corporación de Estudios y Publicaciones. Quito - Ecuador. 2018

Código Civil del Ecuador. Corporación de Estudios y Publicaciones. Quito - Ecuador 2016.

Código de la Niñez y Adolescencia. Corporación de Estudios y Publicaciones. Quito Ecuador 2017. CORNÚ, G. (1998). Droit Civile. La famile. Paris.

Criterio y Recomendaciones Bioéticas sobre la Maternidad Subrogada en Ecuador. Ministerio de Salud Pública, Comisión Nacional de Bioética en Salud.

FERNANDEZ RUIZ-GALVEZ, Encarnación. "Mujeres y Técnicas de Reproducción Artificial. ¿Autonomía o Sujeción? Editorial Comares. Granada, 2002, pág. 161.

Fuente: "Diccionario Fiel web".

https://www.fielweb.com/Index.aspx?145abf6ik651\#app/herramientas. Fecha de consulta: 16 mayo 2019.

Fuente: "Diccionario Fiel web"

https://www.fielweb.com/Index.aspx?145abf6ik651\#app/herramientas. Fecha de consulta: 16/ $05 / 2019$

Fuente: "Real Academia de la Lengua Española". Disponible en: https://dle.rae.es/?id=YZ2is6w. Fecha de consulta: 06 mayo 2019.

Fuente: Red Latinoamericana de Reproducción Asistida (REDLARA). Disponible en: http:// www.redlara.com/aa_espanhol/quem_centros.asp -

https://www.innaifest.com.ec/servicios/soporte-legal. Fecha de consulta: 6 mayo 2019.

Informe de la Comisión Especial de Estudio de la Fecundación 'In Vitro’ y la Inseminación Artificial Humanas. Congreso de Diputados. España. Cortes Generales.

La Cruz Berdejo, J. L., Sancho Rebullida, F., \& Luna Serrano, A. (1997). Derecho de Familia. Barcelona: Bosch.

Ley 14/2006. Técnicas de Reproducción Humana Asistida. España.

Ley 19.585 modifica el Código Civil y otros cuerpos legales enmateria de filiación. Chile.

MENDEZ COSTA, M. (1986). La filiación. Santa Fe: Rubinzal - Culzoni.

MONROY CABRA, MARCO. Derecho de Familia y de Menores. Librería ediciones del Profesional. Octava Edición. Bogotá - Colombia. 2003, página 47.

MORALES LIMONES, PILAR BLANCO ¿ Y tú de quién eres?, Lección inaugural de la Universidad de Extremadura, curso académico 2010/2011.

Observatorio Legislativo. Función Legislativa. Red Latinoamericana por la Transparencia Legislativa. Informe primer debate. Comisión Derecho a la Salud. Disponible en: http:// observatoriolegislativo.ec/legislacion/proyectos-de-ley/proyecto-de-ley-codigo-organico-desalud_65593. Fecha de consulta: 6 mayo 2019. 
SCOTTI, L. (2013) "El reconocimiento de la "maternidad subrogada": una realidad colmada de interrogantes sin respuestas jurídicas”. En Pensar en Derecho, 2013, №1, pp. 267 - 289.

Sentencia de la Corte Constitucional Colombiana T-968-09.

Sentencia No. 11-18-CN/19 de la Corte Constitucional, publicada en Registro Oficial Suplemento 96 de 8 de Julio del 2019

Fecha de recepción: 23 de octubre 2019. Fecha de aceptación: 21 noviembre 2019. 
